archives-ouvertes

\title{
Liquid pressure measurements in a thermally assisted mechanical dewatering process
}

\author{
Etienne Chantoiseau, Patricia Arlabosse
}

\section{To cite this version:}

Etienne Chantoiseau, Patricia Arlabosse. Liquid pressure measurements in a thermally assisted mechanical dewatering process. Chemical Engineering Research and Design, Elsevier, 2010, 88 (8), pp.1078 - 1087. <10.1016/j.cherd.2010.02.002>. <hal-01565974>

\section{HAL Id: hal-01565974 \\ https://hal-mines-albi.archives-ouvertes.fr/hal-01565974}

Submitted on 20 Jul 2017

HAL is a multi-disciplinary open access archive for the deposit and dissemination of scientific research documents, whether they are published or not. The documents may come from teaching and research institutions in France or abroad, or from public or private research centers.
L'archive ouverte pluridisciplinaire HAL, est destinée au dépôt et à la diffusion de documents scientifiques de niveau recherche, publiés ou non, émanant des établissements d'enseignement et de recherche français ou étrangers, des laboratoires publics ou privés. 


\title{
LIQUID PRESSURE MEASUREMENTS IN A THERMALLY-ASSISTED MECHANICAL DEWATERING PROCESS
}

\author{
E. Chantoiseau, P. Arlabosse \\ Ecole des Mines d'Albi Carmaux, RAPSODEE Research Center,
} FRE CNRS 3213, 81013 ALBI CT Cedex 09, France

\begin{abstract}
:
The thermally assisted mechanical dewatering process, investigated in this paper, couples in one stage mechanical dewatering at low pressure $\left(\mathrm{P}_{\text {applied }}<1125 \mathrm{kPa}\right)$ with a moderated heating $\left(\mathrm{T}<80^{\circ} \mathrm{C}\right)$. Former studies emphasized that the separation enhancement depends on the product. To identify the mechanisms involved, a 1D filtration/compression cell is instrumented with pore liquid sensors distributed on the wall. Talc and cellulose in suspensions in salt water are used as test materials. Cake growth and consolidation can be followed through these measurements. With heat supply, the liquid pressure gradient, which has vanished during the consolidation, re-appears in the cake. An additional flow of liquid occurs when the thermal equilibrium is reached in the porous media. This additional flow represents $18 \%$ of the filtrate mass recovered at ambient temperature for talc suspensions and half less for cellulose suspensions.
\end{abstract}

Key words: filtration, consolidation, heat transfer, talc, cellulose, porous media. 


\section{Introduction}

In solid/liquid separation, thickening is usually followed by some form of pressure-assisted dewatering, which can reduce the liquid content from about $95 \%$ to perhaps 60 or $80 \%$, depending on the product dehydrated. This reduction is associated to an increase of the energy consumption from the range $0,001-0,01$ $\mathrm{kWh} . \mathrm{m}^{-3}$ of solvent removed for gravity thickening to $1-10 \mathrm{kWh} \cdot \mathrm{m}^{-3}$ for mechanical dewatering. For many applications, mechanical dewatering cannot ensure sufficiently low liquid content and thermal drying should be used. Though successful, the typical energy consumption of the dryers is of the order of 800 $1000 \mathrm{kWh} \cdot \mathrm{m}^{-3}$ of solvent removed. The energy efficiency of the overall solid/liquid separation process is related to both the liquid content at the dryer inlet and the dryer efficiency. Consequently, research in progress tends to enhance the dewatering ability of conventional mechanical processes. Intensification of mechanical dewatering processes can take several forms: simultaneous application of an electric field (Lee et al., 2007; Curvers et al., 2007), possibly pulsed (Grimi et al., 2007; Gachovska et al., 2006), superimposition of ultrasounds (Smythe and Wakeman, 2000) or with heat supply (Clayton et al., 2006; Mahmood et al., 1998; Peuker and Stahl, 2001; Couturier et al., 2003). For a few years now, we specifically investigate a thermally assisted mechanical dewatering (TAMD) process, which couples mechanical dewatering at low pressure (usually $\left.\mathrm{P}_{\text {applied }}<1125 \mathrm{kPa}\right)$ with a moderate heating $\left(\mathrm{T}<80^{\circ} \mathrm{C}\right)$ of the walls of the apparatus in contact with the product. The proposed combination of pressure and temperature leads to the elimination of the solvent in liquid phase and, for some 
products, results in a significant energy saving on the overall separation process. For instance, after processing bentonite sludge - clay suspension used as a sealing agent in the construction industry - under moderate operating conditions ( $\mathrm{T}_{\text {wall }}=90^{\circ} \mathrm{C}$ and $\mathrm{P}_{\text {applied }}=340 \mathrm{kPa}$, followed by a final pressure step to $1650 \mathrm{kPa}$ ), the dry solid content reaches $81.43 \%$ (Mahmoud et al., 2008). Under the same operating pressures but at ambient temperature, the dry solid content of the bentonite sludge would reach only $30 \%$. Thus, at the end of its re-use cycle, the TMAD dewatered clay can be landfilled at low costs and without regulation difficulty. The separation enhancement depends on the product. Indeed, with the same operating conditions, the dry solid content increase is only of 6.36 and $4.83 \%$ for talc and cellulose suspensions, respectively. Response surface methodology, used to evaluate the effects of the processing parameters, emphasizes that significant separation enhancement, like for bentonite sludge, results only from thermal effects and that additional flows of filtrate occur at long times (Mahmoud et al., 2008). Consequently, understanding the mechanisms involved in the thermally assisted mechanical dewatering and leading to a significant increase of the final dry solid content of the product is essential for the filter design and for the identification of the potential market of the technology.

During the mechanical dewatering process, the so-called filtration and expression stages occur successively. In the filtration stage, the compressive piston pushes the slurry in the direction of the filter medium. The liquid phase passes through the filter medium while the solids are held. As a result, a filtration cake builds up. The flow of liquid through this cake induces drag forces on the solid matrix, 
resulting in a gradual decrease of the liquid pressure in the porous media and a gradual increase of the compressive stress on the solid phase, also called the solid compressive stress. When the piston reaches the cake, the filtration stage ends and expression begins. The piston load, initially supported by the liquid phase, is then distributed between the liquid and solid phases. The porous media is progressively compressed into a more compact form, as liquid water is expelled. After a certain time, the volume of the porous media does not change anymore: the cake is consolidated and the amount of water in the cake is minimum. The filterability of the cake and its ability to be compressed are essential parameters of the separation process. They largely depend on the cake structure and properties, which are fixed by the operating conditions and the suspension properties. The design of the conventional and thermally assisted filters requires the knowledge of the evolution of the cake structure and properties during its formation and its expression. Among these properties, a detailed attention must be paid to the volume fraction of solids (also called solidosity) and permeability distributions along the cake.

Cake properties are usually described like functions of the solid pressure, introduced by Tiller and Crump (1977). Assuming a point contact between the particles, the solid pressure is defined as the ratio between the force transferred between the particles and the filter section. Experimentally, the relations between the solid pressure and the local cake properties, also called constitutive equations, are determined thanks to a compression - permeability cell (C-P cell). This apparatus was first introduced by Ruth (1946) and the postprocessing data procedure improved by Lu et al. (1998) to correct the effect of side-wall frictions. 
Solidosity and permeability are computed from macroscopic data: the solidosity of the cake is computed from its volume, knowing the mass of solid introduced and its density, while the permeability is determined from the filtrate volumetric flow rate and the pressure drop across the cake. The specific resistance, defined as the reciprocal of the product of solidosity, permeability and solid density, results from these calculations. Computed data are average values, corresponding to the equilibrium state reached for the applied pressure, namely the applied load divided by the cell section. This applied pressure is supposed to be equivalent to the solid pressure appearing during the filtration-expression process. These studies are of great interest for characterizing the average properties of the cake in a equilibrium state. To take into account the dynamics of the process, local measurements in the forming cake must be performed. Classically, local solidosity and/or local liquid pressure in the filter cake are registered as a function of time. Evolution of the local solidosity during dewatering experiments can be achieved using electrical resistance measurements (Chase and Arconti, 1995), NMR imaging (La Heij et al., 1996), x or $\gamma$-ray measurements (Sedin et al., 2003). Although more complicated to implement, NMR and $\gamma$-ray techniques offer much better measuring accuracy (less than 1\%) and are nonintrusive, even if Tarleton (1999) proves that $2 \mathrm{~mm}$ electrodes intrusions from the cell wall cause negligible effects on cake formation. All these techniques give access to the average solidosity of a cake slice, the measurements being simultaneously performed at different heigths from the filter. For a long time, the local liquid pressure in filter cakes were measured using protruding capillary tubes connected to external force 
transducers (Fathi Najafi and Theliander, 1995). According to the experimental setups, the capillary tubes, of different lengths, were attached to the cell wall, extended downwards from the top of the cell or extended through the filter medium, and penetrated more or less deeply in the cake. Recently, Tarleton (2008) experimented titanium micro-pressure transducers attached to holders and to microbore tubes, which protruded $2 \mathrm{~mm}$ into the cell. Ten probes were positioned in a spiral arrangement around the cell periphery. The first probe was located at $0.5 \mathrm{~mm}$ above the filter medium and the first seven were within $3.3 \mathrm{~mm}$ of the filter medium. The transducers were able of monitoring the transient liquid pressures generated in the forming talc or calcite cakes with a response time lower than $0.1 \mathrm{~s}$ for constant or stepped pressure filtration experiments. For a $600 \mathrm{kPa}$ applied pressure, the formation of a $9.3 \mathrm{~mm}$ height cake lasts $125 \mathrm{~s}$, as emphasized by the sudden reduction in the liquid pressure measured by the sensor positioned at that place. For the $100-600 \mathrm{kPa}$ applied pressure range, the measured liquid pressure profiles for talc were of concave appearance between the medium surface and the top of the cake. As expected for the same filtration time, a higher applied pressure displaces the normalised pressure profiles above and to the left, indicating a thicker and more compact cake, while the plot of normalised cake height vs. liquid pressure proves to be independent of applied pressure, as suggested by Shirato et al. (1987).

With the operating conditions of the TAMD process, it is necessary to gather local data not only during the filtration phase but also during the following expression. 
We thus specifically investigate the liquid pressure profiles in talc and cellulose cakes using non intrusive pore pressure sensors.

\section{Experimental set-up}

\section{Filtration Expression Cell}

At the laboratory scale, the experimental set up comprises a filtration/compression cell inserted in a CARVER ${ }^{\circledR}$ hydraulic press (Carver Inc., Wabash, United State), which has a maximum pressing capacity of $14800 \mathrm{kPa}$ and provides the pressure required to progress a downward filtration and expression.

The cell (cf. Figure 1) consists of a compressive piston, a hollowed cylindrical vessel and a filter medium. The filtration chamber has a diameter of $148 \mathrm{~mm}$ and a maximum height of $60 \mathrm{~mm}$. In spite of its low mechanical resistance, Teflon ${ }^{\mathrm{TM}}$ was selected as constitutive material of the vessel walls to minimize the frictions with the piston. Consequently, a stainless steel external jacket was added to ensure the mechanical resistance of the unit. The cell is fitted with a planar medium of $165.2 \mathrm{~cm}^{2}$ area, which is composed of a microfibers glass filter (Whatman International Ltd, Maidstone, UK) deposited on a Teflon ${ }^{\mathrm{TM}}$ grid. To investigate the temperature impact, three electric resistances are inserted in the upper part of the compressive piston, made of copper to reduce thermal inertia. Each resistor can supply up to $350 \mathrm{~W}$. Three thermocouples, including the one for the temperature regulation, are introduced into the piston. Knowing the temperatures at various positions from the front side of the piston, the inverse conduction 
problem in the copper wall can be solved to estimate the heat flux density exchanged between the compressive piston and the product. The accuracy of these sensors with theirs acquisition lines was evaluated at $\pm 0.1^{\circ} \mathrm{C}$.

The filtrate recovered in the collector flows out into a container on the computer interfaced balance. The mass is automatically weighted at set time intervals of $1 \mathrm{~s}$. Finally, a movement sensor gives the thickness of the sample according to time.

\section{Liquid pressure measurements}

To investigate liquid pressure profiles in the forming cake and during its expression, four PDCR-81 pore pressure sensors (Druck Ltd., Leicester, England) are implemented in the cell wall. The sensors are $11.2 \mathrm{~mm}$ in length and $6.4 \mathrm{~mm}$ in diameter, with a maximum measurable pressure of $1500 \mathrm{kPa}$ and a combined non linearity and hysteresis (NLH) of $\pm 0.2 \%$ of the best straight line (BSL). The temperature compensated range varies between -20 and $+120^{\circ} \mathrm{C}$. Within the compensated temperature range, the thermal zero shift is $\pm 0.05 \%$ of the full scale and the thermal sensitivity shift of $\pm 0.2 \%$ of reading per $\operatorname{degC}$.

The sensors are inserted in holes drilled inside the cell side wall at 5, 10, 15, and $20 \mathrm{~mm}$ from the filter medium (see

Figure 2a). The connection between the ceramic porous plate of the pressure sensor and the suspension is carried out thanks to an opening of $3 \mathrm{~mm}$ in diameter and $1 \mathrm{~mm}$ in length (see 
Figure 2b). Thus implemented, the pressure sensors are non intrusive. For a correct measurement, all the ceramic porous media and all the openings must be carefully filled with water at the beginning of each experiment, to ensure the continuity of the liquid phase.

Calibration of the liquid pressure measurement system was performed with pure water at ambient temperature and with the piston heated to $80^{\circ} \mathrm{C}$. The pore pressure sensor manufacturer provided a certificate of calibration for each sensor. For all of them, the experimental deviation in reading from the ideal point at zero relative pressure is at least six times lower than the zero offset given by the supplier. To quantify the measure uncertainty of the measurement system, stages of constant pressure were applied with the hydraulic press, called the standard in the following, which was calibrated beforehand using a load cell (Omegadyne Inc., Sunbury, USA). The applied pressure ranges from 340 to $1125 \mathrm{kPa}$. As displayed on

Figure 3 , the regulation system of the standard involves large fluctuations of the applied pressure around the set value. For a reference pressure set to $318.9 \mathrm{kPa}$, the standard deviation on the measurements is $\pm 10.3 \mathrm{kPa}$. For higher applied pressures, the standard uncertainty reaches a constant value of $\pm 8.8 \mathrm{kPa}$. 
The uncertainty of calibration of the pore pressure sensor (type B evaluation), the effect of temperature on the sensor (type B evaluation) and the uncertainty introduced by the regulation system (type A evaluation) were identified like the three most important contributory factors to the measure uncertainty. Knowing their standard uncertainties, the combined standard uncertainty and the expanded uncertainty at $95 \%$ confidence level (with a coverage factor $\mathrm{k}$ set to 2 ) were estimated for each stage of constant pressure.

Figure 4 and

Figure 5 illustrate the transmitted pressure versus the applied one for the experiments performed at ambient temperature and with the piston heated to $80^{\circ} \mathrm{C}$, respectively.

According to the measure accuracy, the pore pressure measurement device can be regarded as validated. The accuracy of the measurements decreases when the temperature increases. For a piston temperature set to $80^{\circ} \mathrm{C}$ and a standard pressure of $340 \mathrm{kPa}$, the temperature of the water at bottom of the cell reaches $74^{\circ} \mathrm{C}$ at thermal equilibrium. This induces an expanded uncertainty of $57.7 \mathrm{kPa}$ with a coverage factor $\mathrm{k}$ of 2 . For the same operating pressure, the expanded uncertainty with a coverage factor $\mathrm{k}$ of 2 decreases to $20.7 \mathrm{kPa}$ at ambient temperature. 
These experiments are regularly reproduced to check the good operating condition of the pore pressure sensors, especially to detect a possible blocking of the ceramic porous media.

\section{Materials and procedure}

Former studies and the scientific literature showed that the efficiency of the TAMD process depends on the product. For talc suspensions, the profit induced by the heat supply is tiny. Nevertheless, as it is frequently used as model material, experiments were performed with suspensions of talc in salt water $(0.3 \mathrm{NaCl}$ mol/l). Microcrystalline cellulose, also dispersed in salt water $(0.3 \mathrm{NaCl} \mathrm{mol} / \mathrm{l})$, was used as second model material. This choice was done according to the shape of the particles and to its organic composition. Table 1 summarizes some basic physical and thermal properties of the two dry powders.

Table 1: Basic properties of the dry powders

\begin{tabular}{|l|c|c|c|}
\hline \multicolumn{1}{|c|}{ Parameters } & Unit & Talc & Cellulose \\
\hline Shape & - & Sheet & Fibrous \\
\hline Density & $\mathrm{kg} \cdot \mathrm{m}^{-3}$ & 2796.7 & 1546 \\
\hline Specific surface & $\mathrm{m}^{2} \cdot \mathrm{kg}^{-1}$ & 3208 & 5510 \\
\hline Specific heat & $\mathrm{J} . \mathrm{kg}^{-1} \cdot \mathrm{K}^{-1}$ & 290 & 470 \\
\hline Thermal conductivity & $\mathrm{W} \cdot \mathrm{m}^{-1} \cdot \mathrm{K}^{-1}$ & 0.1 & 0.16 \\
\hline Median particle size & $10^{-6} \mathrm{~m}$ & 11 & 17.4 \\
\hline
\end{tabular}


To highlight the phenomena occurring at long times - during the heating of the consolidated cake - thanks to pressure liquid measurements, the consolidated cakes must be thick enough. Concentrated suspensions, $17 \% \mathrm{v} / \mathrm{v}$ of talc in salt water and $14 \% \mathrm{v} / \mathrm{v}$ for cellulose, are prepared. The solid is introduced gradually into a vessel filled with slowly stirred salted water. When the desired mass concentration is reached, agitation is stopped and the suspension is settled for several hours to leave time to the air to diffuse. Before its use, the agitation is restarted to homogenize the suspension. Under $340 \mathrm{kPa}$ and with the selected initial solid volume fractions, one liter of the suspension initially poured in the filtration/expression cell approximately generates a $20 \mathrm{~mm}$ thick consolidated cake.

Before the introduction of the suspension into the cell, the piston is heated to the prescribed temperature, the filtration medium is pre-wetted and the filtrate collector is pre-filled with water to avoid filtrate accumulation at the beginning of the dewatering experiment. After pouring the required quantity into the cell, the mass of the remaining suspension is measured and its water content determined according to the AFNOR standard procedure $\mathrm{N}^{\circ} \mathrm{X} 31-505$, which recommends a drying at $105^{\circ} \mathrm{C}$ for 24 hours. As a result, the initial masses of liquid and solids poured in the filtration/expression cell are known with a standard uncertainty of \pm 0.03 and $0.02 \mathrm{~g}$, respectively.

Dewatering experiments are performed with the hydraulic pressure set to 340,730 or $1125 \mathrm{kPa}$ and with the piston kept at ambient temperature $\left(22^{\circ} \mathrm{C} \pm 1^{\circ} \mathrm{C}\right)$ or heated to 50 or $80{ }^{\circ} \mathrm{C}$. Each experiment was repeated 3 times. The applied 
pressure, the liquid pressures, the piston temperatures, the electrical power, the piston displacement and the cumulative mass of filtrate are recorded during each experiment. Furthermore, at the end of the experiment, the final thickness of the cake is measured with a calliper and its final moisture content calculated according to the X31-505 AFNOR standard procedure to check the mass's conservation law.

In spite of the fluctuations of the applied pressure introduced by the regulation system, the impact on the macroscopic structure of the filtration cake, evaluated in terms of moisture content and thickness, is reduced. For an applied pressure of $344 \mathrm{kPa}$, the measuring accuracy, computed on the basis of the three replicates, is $\pm 0.6 \%$ for the final moisture content and $\pm 3 \%$ for the cake thickness.

\section{Experimental results and discussion}

\section{Preliminary raw datum processing}

Figure 6 shows the cumulative masses of filtrate as well as the applied pressures for three dewatering experiments of cellulose suspensions at $1125 \mathrm{kPa}$ and ambient temperature. Most of the dewatering takes place before the set pressure is reached. The measured mass of filtrate $(\mathrm{m})$ vs. time $(\mathrm{t})$ is reproducible, the standard deviation between the three repeat tests being less than $\pm 0.03 \mathrm{~kg}$.

The pressurization of the whole device depends on the displacement rate of the lower plate of the hydraulic press, on which the hollowed cylindrical vessel and the filter medium rest. This velocity is controlled manually, which explains the 
discrepancies in the pressure rise observed during the transient stage. For a given time, the applied pressure may differ from $20 \%$ from one experiment to another, what explains the standard deviation observed on the mass. For a pressure applied of $1125 \mathrm{kPa}$, the set pressure is reached after approximately 90 seconds. It is evident from Figure 6 that the duration of this transient stage depends on the set pressure, the cake composition and, to a lesser extend, on the temperature. Each value reported in Table 2 is the average of the transient stage durations of all the experiments carried out with the given operating conditions.

To compare the data measured under different operating conditions, the results will be presented according to a non-dimensional time $\left(\mathrm{t}_{\text {adim }}\right)$, obtained by dividing the acquisition time by the duration of the transient stage given in Table 2 . Moreover, this change of variable reduces the dispersion of the data, as can be seen on

Figure 7.

Table 2: Transient durations.

\begin{tabular}{|c|c|c|c|}
\hline \multicolumn{2}{|c|}{ Operating conditions } & \multicolumn{2}{|c|}{ Transient stage duration } \\
\hline Set pressure & Piston temperature $\left({ }^{\circ} \mathrm{C}\right)$ & Talc & Cellulose \\
\hline \multirow[t]{2}{*}{340} & $22^{\circ} \mathrm{C}$ & 60 & 43 \\
\hline & $80^{\circ} \mathrm{C}$ & 61 & 49 \\
\hline 730 & $50^{\circ} \mathrm{C}$ & 92 & 80 \\
\hline \multirow[t]{2}{*}{1125} & $22^{\circ} \mathrm{C}$ & 109 & 88 \\
\hline & $80^{\circ} \mathrm{C}$ & 109 & 94 \\
\hline
\end{tabular}




\section{Liquid pressure profiles during cake formation and consolidation at ambient temperature}

The phenomenology of cake formation and consolidation described in the introduction will be illustrated in the following through the data measured during the first 120 seconds of an experiment of talc dewatering at $1125 \mathrm{kPa}$ and ambient temperature. The applied pressure, the thickness of the sample as well as the pore pressures measured at 5,10,15, and $20 \mathrm{~mm}$ from the filter medium are plotted in Figure 8 versus the dimensionless time scale. According to the expanded measurement uncertainty (20.7 $\mathrm{kPa}$ at ambient temperature), the recorded variations of pressure are significant during the whole process.

From the phenomenological point of view, the filtration is the first stage of the mechanical separation. The growth of the cake can be followed through the liquid pressure measurements. Indeed, while the pore pressure sensor is in contact with the suspension, the measured liquid pressure is the same as the current applied pressure: the particles in the suspension are sufficiently apart to carry out zero compressive pressure. In the cake, particles are in contact, raising the solid compressive pressure and inducing a corresponding reduction in liquid pressure. Therefore, when the upper surface of the cake reaches the position of a pore pressure sensor, the measured liquid pressure becomes the pore liquid pressure and its value is lower than the applied pressure, as stated by the Darcy's law. Liquid pressure measurements give thus an indirect evaluation of the cake height. 
For instance, the forming cake reaches $10 \mathrm{~mm}$ high at $\mathrm{t}_{\mathrm{adim}}=0.12$. The filtration stage is associated to a fast reduction of the thickness of the whole sample, i.e. the suspension and the forming cake. Transition towards expression occurs for $t_{\text {adim }}$ closed to 0.5. All the pore pressures are then lower than the applied pressure and their values decrease gradually while the cake thickness tends towards a horizontal asymptote. Let us specify that the measurement associated with the sensor located at $20 \mathrm{~mm}$ is sullied with error from $\mathrm{t}_{\mathrm{adim}}=0.5$. Indeed, the thickness of the cake becomes lower than $22 \mathrm{~mm}$, and the top of the sensor is partially sealed by the piston. The pore liquid pressures vanish beyond $t_{a d i m}=1.2$.

Under the same operating conditions, the growth of cellulose cake is faster (see Figure 9), since the measured pore liquid pressures deviate more quickly from the pressure applied. Transition towards expression occurs for $t_{\text {adim }}$ closed to 0.4. As expected, the physical mechanisms involved during the compression are appreciably different with cellulose. The measured pressures of pore are lower than that achieved with talc suspension and remain appreciably constant or even increase for $0.7<\mathrm{t}_{\text {adim }}<1$, indicating a higher compressibility of the cellulose cake. This compressibility can be macroscopic, if the particles constituting the cake tend to be rearranged, or particulate, if the individual particles tend to become deformed. Once the set pressure reaches (for $t_{a d i m}=1$ ), the pore pressures decrease gradually. 
The liquid pressure profiles are compared for talc and cellulose suspensions dewatered at $1125 \mathrm{kPa}$ and ambient temperature. As in Sedin et al. (2003) and Tarleton (2008), the measured liquid pressure profiles are similar in form and more or less of concave appearance between the filter medium surface and the top of the cake during filtration $\left(\mathrm{t}_{\mathrm{adim}}<0.4\right)$. Talc cake is formed more quickly than that of cellulose but the cellulose cake grows faster. This can be related to the structure of the forming cake. Indeed, as the talc cake is more compact, its growth is limited by the filtration resistance, that the growing cake generates itself. For cellulose, the cake is more porous, which explains why the pressure loss is less and the growth faster.

Liquid pressure profiles are plotted in

Figure 11 for talc suspension and in Figure 12 for cellulose suspension, both dewatered at $1125 \mathrm{kPa}$ and ambient temperature. For a question of readability, the measure uncertainties were not drawn on these graphs. Nevertheless for $t_{\text {adim }}=0.4$, the expanded measure uncertainty at $95 \%$ confidence level is $11 \mathrm{kPa}$ near the filter medium and $14 \mathrm{kPa}$ far away from the filter medium. For $\mathrm{t}_{\mathrm{adim}}=0.7$, its value decreases to $3 \mathrm{kPa}$ for all the sensors.

During filtration, the liquid pressure is at its lowest near to the filter medium since the particles comprising the cake are closest together. These particles undergo not only frictions due to the flow of liquid in the interstices but also the efforts 
transmitted by the neighboring particles. As time progressed in filtration, the cake thickness and, consequently, the weight of the particles above those already constituting the cake increases, what explains the decrease of the liquid pressure close to the filter medium. Further away from this medium, interactions between the particles comprising the cake are lower and the pore pressure higher. Above the cake, the liquid pressure is equal to the applied pressure. These results are consistent with those published by Tarleton (2008).

When the top of the cake comes into contact with the piston, part of the applied pressure is immediately transferred toward the connected solid particles, which induces a corresponding reduction in the liquid pressure. The ratio $P_{\text {liq }} / P_{\text {applied }}$ becomes thus lower than one. As time progressed in expression, the pressure ratio further decreases, just like the pressure of the liquid in the cake and the liquid pressure gradient. For $t_{a d i m}>0.7$, no gradient of pore liquid pressure remains in the cake, which is almost consolidated.

\section{Influence of the heat supply on the separation}

Figure 13 displays the cumulative masses of filtrate versus the non-dimensional time for talc suspensions dewatered at 340 and $1125 \mathrm{kPa}$, at ambient temperature or with the piston heated to $80^{\circ} \mathrm{C}$. The irregularities, which can be observed on the mass curve at $340 \mathrm{kPa}$ for a non-dimensional time of 4 for instance, result from 
temporary water retentions inside the hose between the water collector and the scale. More than $95 \%$ of the filtrate is extracted during the transient stage, defined by the non-dimensional time lower than 1. As expected (Mahmoud et al., 2008), a rise in the pressure applied increases the amount of filtrate significantly, almost $15 \%$, whereas the influence of temperature on the dewatering kinetics is negligible. Once the set pressure is reached, the cumulative mass of filtrate tends gradually towards a horizontal asymptote for the two experiments performed at ambient temperature, indicating that the limit dry solid content is reached. With heat supply, a residual flow of liquid appears after several hours of experiment. This flow is all the more important as the applied pressure is low and does not result in a significant variation of the cake thickness. For a pressure applied of 340 $\mathrm{kPa}$, the gain is of approximately $100 \mathrm{~g}$ of water. For a piston temperature set to $80^{\circ} \mathrm{C}$, this phenomenon occurs beyong $\mathrm{t}_{\mathrm{adim}}=2.10^{2}$.

The same macroscopic behaviours are observed with the cellulose suspensions, even if the recovered quantities are smaller (see Figure 14). For the experiment at $1125 \mathrm{kPa}$, this additional flow is not even visible on the given representation. Moreover, this residual flow appears later with cellulose cake.

To investigate the mechanisms involved during the thermally assisted mechanical dewatering, let us analyse the liquid pressure history firstly during cake formation and secondly just before the residual flow of liquid.

The liquid pressure profiles measured during the cake formation are compared on 
Figure 15 for cellulose suspensions dewatered under $1125 \mathrm{kPa}$, at ambient temperature or with the piston heated to $80^{\circ} \mathrm{C}$. Near to the filter medium, the heat supply has no influence on the measured liquid pressure profiles. Close to the piston, the measured liquid pressure seems to deviate faster from the pressure applied when the piston is heated. But taking into account the expanded measure uncertainty at $95 \%$ confidence level, estimated at $30.6 \mathrm{kPa}$, no conclusion can be drawn from these experimental results. When expression occurs, the liquid profile histories are similar whatever the piston temperature.

From the thermal point of view, the system can be modelled like a wall maintained at a constant temperature in contact with a motionless suspension. Indeed, the suspension is pushed by the piston toward the filter medium but the relative velocity between the piston and the suspension is null. The time required for the thermal energy to diffuse from the heated wall toward the suspension depends on the dry solid content of the suspension and on the density, specific heat and thermal conductivity of its components (see Table 1 for the solid properties). The thermal conductivity of the suspension is a function of the arrangement of the solid particles in the suspension. The two typical structural model, i.e. series and parallel heat transfer models, were used to calculate the effective thermal conductivity of the saturated suspension. According to the initial solidosity, the effective thermal conductivity of the suspension ranges between 0.43 and $0.54 \mathrm{~W} \cdot \mathrm{m}^{-1} \cdot \mathrm{K}^{-1}$. For a initial water content of $3.59 \mathrm{~kg}$ of water $/ \mathrm{kg}$ of dry solid, this finally gives a characteristic time of diffusion ranging between 6.8 and 8.4 seconds. These values correspond to the theoretical time necessary to raise of 
one degree Celsius the temperature of the suspension on a thickness of one millimetre. Thus, when the upper surface of the cellulose cake reaches the sensor located at $15 \mathrm{~mm}$ from the filter medium for $\mathrm{t}_{\mathrm{adim}}=0.3$, i.e. $\mathrm{t}=8.2$ seconds, the heat has diffused only on the first two millimetres of the suspension. In the same time, the total thickness of the sample, i.e. the remaining suspension and the forming cake, is $37 \mathrm{~mm}$. Since the temperature gradient is established very slowly, the cake is forming at ambient temperature and the filtration can be seen like an isothermal stage, even in the assisted dewatering process. This justifies that no difference appears on the macroscopic and microscopic scales.

At the time of the transition towards the expression stage, which occurs at $t=40$ seconds for cellulose suspension dewatered at $340 \mathrm{kPa}$ with the piston heated to $80^{\circ} \mathrm{C}$, the time required for the thermal energy to be transported with the moving fluid can be calculated from the Peclet number and the characteristic time of thermal diffusion in the liquid phase. The Peclet number is defined as the product of the liquid velocity by the characteristic dimension, divided by the thermal diffusivity of the liquid phase. At the macroscopic scale, the height of the suspension can be used as the characteristic dimension. With the liquid velocity determined from the experiments, the Peclet number is 60.3. As Pe $>1$, convection dominates diffusion and, consequently, large temperature gradients can exist in the porous media. The characteristic time of thermal diffusion in the liquid, defined as the square characteristic length divided by the thermal diffusivity of the water, is 5268.5 seconds. As a result, the characteristic time of advection is 87.4 seconds. Thus, from a purely theoretical point of view, the 
temperature should increase near the filter medium after 127.4 seconds. Experimental measurements confirm this theoretical result. A temperature sensor was introduced near the filter medium to measure the temperature of the flowing liquid. Figure 16 shows the experimental results: the measured temperature remains constant during the 139 first seconds and then increases gradually up to $68^{\circ} \mathrm{C}$. The residual flow occurs when the thermal equilibrium is reached, as emphasized on Figure 16.

At ambient temperature, measurements confirms that the liquid pressure gradient vanishes during cake consolidation (see

Figure 11 for talc suspension and Figure 12 for cellulose suspension). When the experiments are stopped, the residual gradient, calculated from the liquid pressure at 15 and $5 \mathrm{~mm}$ from the filter media, is at the most of $10^{6} \mathrm{~Pa}^{-1}$. If heat is supplied, the liquid pressure gradient, which has vanish after the end of the first consolidation, re-appears after several hours of experiment.

Figure 17 shows the temporal evolutions of the liquid pressure gradient for the cellulose (a) and talc (b) suspensions, dewatered at 340 or $1125 \mathrm{kPa}$, in the thermally assisted process. According to the temperature level, the expanded uncertainty at $95 \%$ confidence level is equal to $54.8 \mathrm{kPa}$ when the measured liquid pressure is $100 \mathrm{kPa}$ and to $104.3 \mathrm{kPa}$ when the measured pressure is $200 \mathrm{kPa}$. The 
gradient results from an overpressure which appears in the upper part of the cake. The amplitude of the gradient is more important in talc cakes, which are moderately compressible, but also when the load applied to the cake is weak and the cake less compact. This gradient persists in the porous media until the liquid flows suddenly. The liquid pressure gradient disappears then or, more precisely, tends towards the asymptotic value of $10^{6} \mathrm{~Pa}^{-1}$. The few temperature measurements carried out thanks to the intrusion of a thermocouple into the cake show that this flow occurs when the thermal balance is reached in the porous media.

One can expect that the temperature induces a thermal expansion of the liquid phase in the cake. As the liquid is almost incompressible, the thermal expansion in the upper part of the cake would inevitably result in a liquid pressure increase. This local overpressure would push the liquid downwards. But, as the lower part of the cake is colder, the viscosity of water is higher and as, in the same time, the cake permeability is less, the liquid cannot flow out easily. With the temperature increase, the lower part of the cake opposes gradually less resistance to the fluid flow and the pressure loss decreases. When the overpressure becomes larger than the pressure loss, the fluid flows out and the liquid pressure gradient vanishes.

\section{Conclusion}

Liquid pressure profiles were measured in talc and cellulose cakes using non intrusive pore pressure sensors. Thanks to the implemented breadboard construction, the cake creeping is not disrupted and the pressure profile can be 
characterized during the cake formation but also during its expression. Cake growth can be followed through these measurements.

As expected, at the beginning of the experiment, the liquid pressure is at its lowest near to the filter medium. As time progressed in filtration, the cake becomes thicker and the pressure value decreases close to the filter medium,. When the cake is consolidated, the pressure is homogenized little by little in the cake. The physical mechanisms are appreciably different between cellulose and talc suspensions. Talc cake is formed more quickly but cellulose cake grows faster.

When heat is supplied through the compressive piston, the liquid pressure gradient re-appears in the consolidated cake. Calculations of thermal characteristic times of diffusion and convection for the intensified process show that the filtration and most of the consolidation are carried out at ambient temperature. Once the thermal balance is reached in the porous media, an additional flow is noted. The quantity of filtrate collected depends on the consolidation of the cake and on the cake composition. For a pressure applied of $340 \mathrm{kPa}$, the gain is of approximately $100 \mathrm{~g}$ of water, i. e. $18 \%$ of the filtrate mass recovered at ambient temperature, for talc suspensions and half less for cellulose suspensions. 


\section{List of figures}

Figure 1: detail of the experimental cell. (1) Electric resistance; (2) Copper piston;

(3) Fluxmeter; (4) Steel jacket; (5) Teflon vessel; (6) Filtrate collector;

(7) Filter medium.

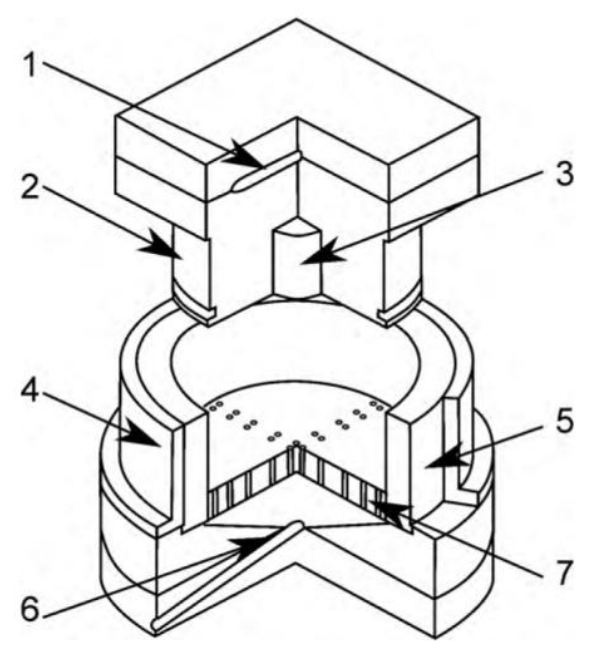

Figure 2: Location of the sensor in the cell wall. (a) Overview; (b) Detail.

(a)

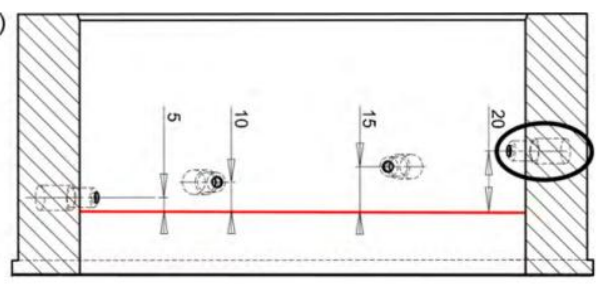

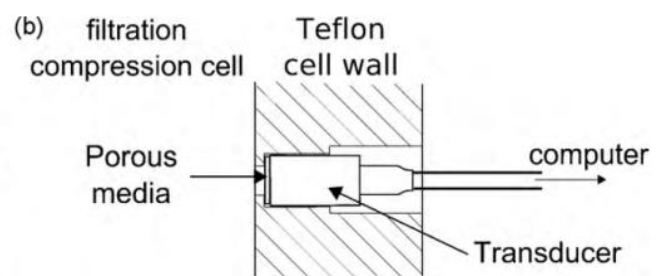


Figure 3: Measure uncertainty introduced by the regulation system of the standard

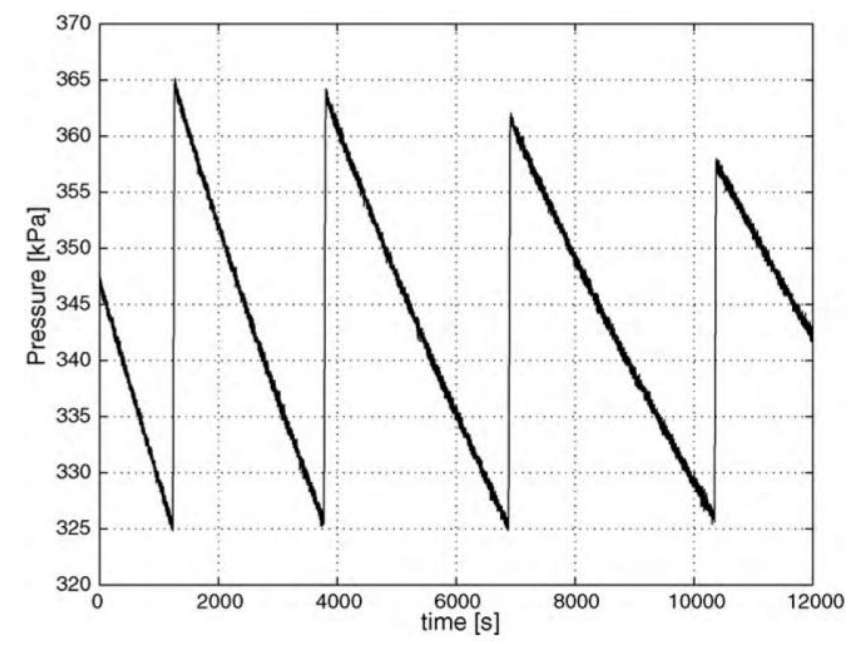

Figure 4: Calibration at ambient temperature of the measurement system associated to the sensor located at $5 \mathrm{~mm}$ above the filter medium.

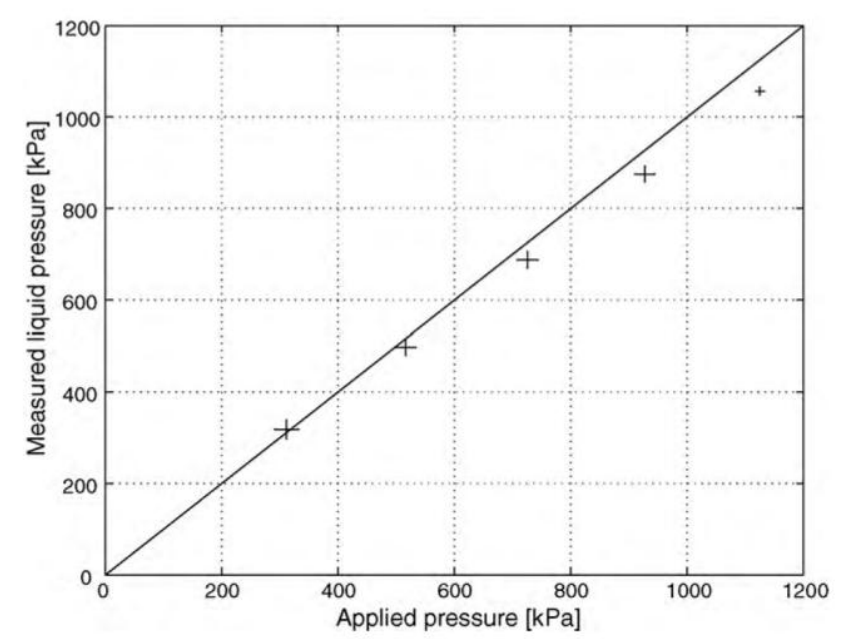


Figure 5: Calibration of the measurement system associated to the sensor located at $5 \mathrm{~mm}$ above the filter medium for a piston temperature of $80^{\circ} \mathrm{C}$.

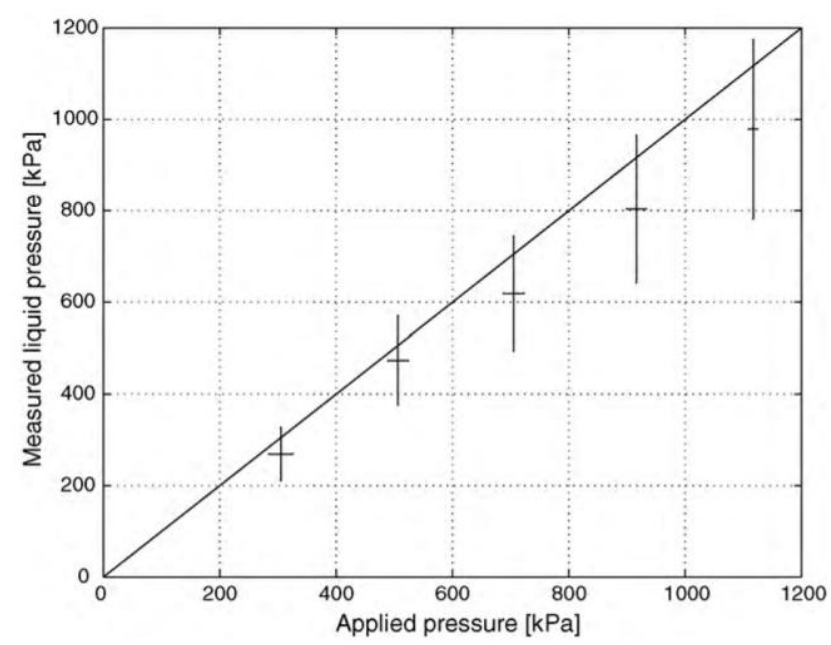

Figure 6: Filtrate masses (dotted lines) and applied pressure (full lines) for three repeat tests performed at $1125 \mathrm{kPa}$ and ambient temperature with cellulose suspension

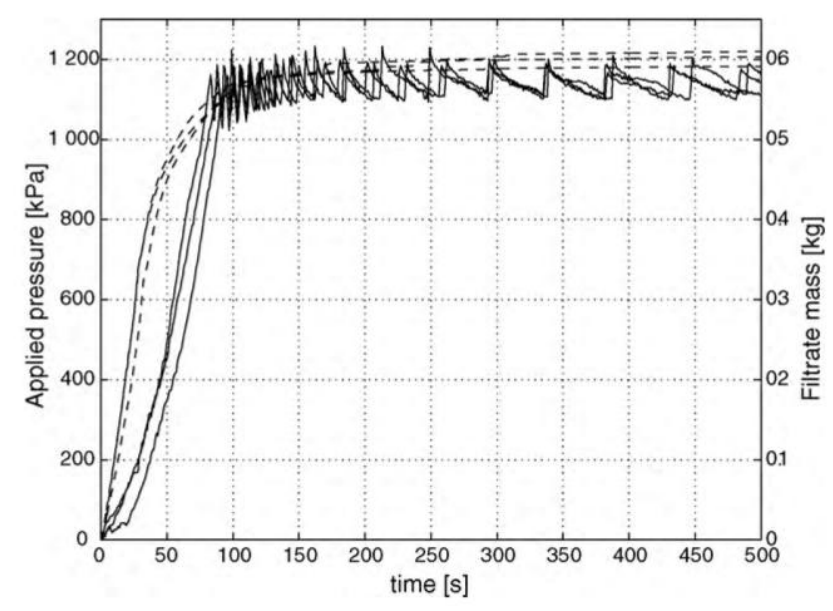


Figure 7: Filtrate masses (dotted lines) and applied pressures (full lines) versus the dimensionless time scale for the three repeat tests performed at 1125 $\mathrm{kPa}$ and ambient temperature with cellulose suspension.

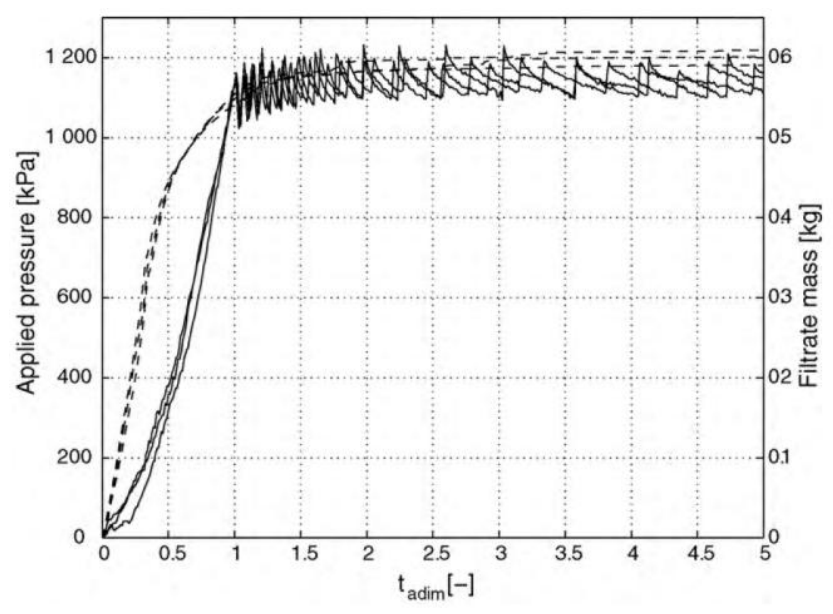

Figure 8: Applied pressure, liquid pressures and sample thickness during talc suspensions dewatering at $1125 \mathrm{kPa}$ and ambient temperature.

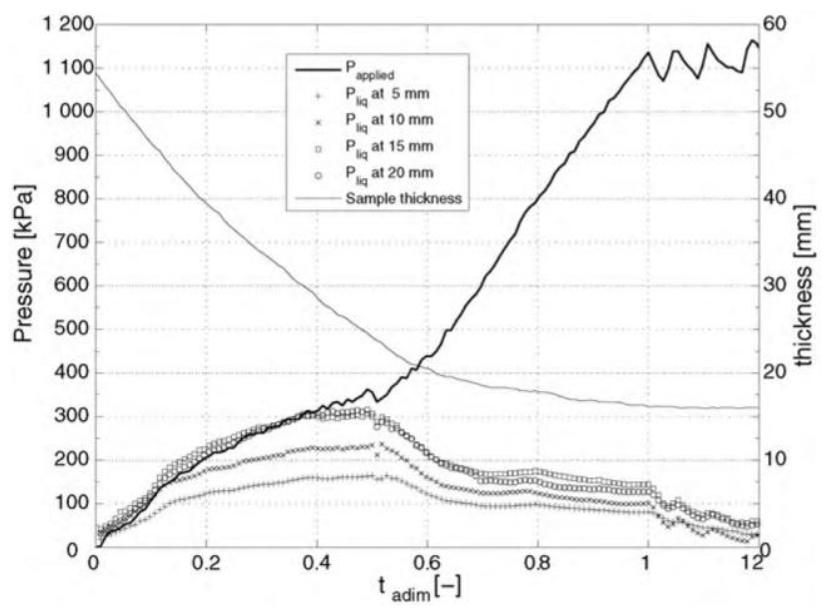


Figure 9: Applied pressure, liquid pressures and sample thickness during cellulose suspensions dewatering at $1125 \mathrm{kPa}$ and ambient temperature

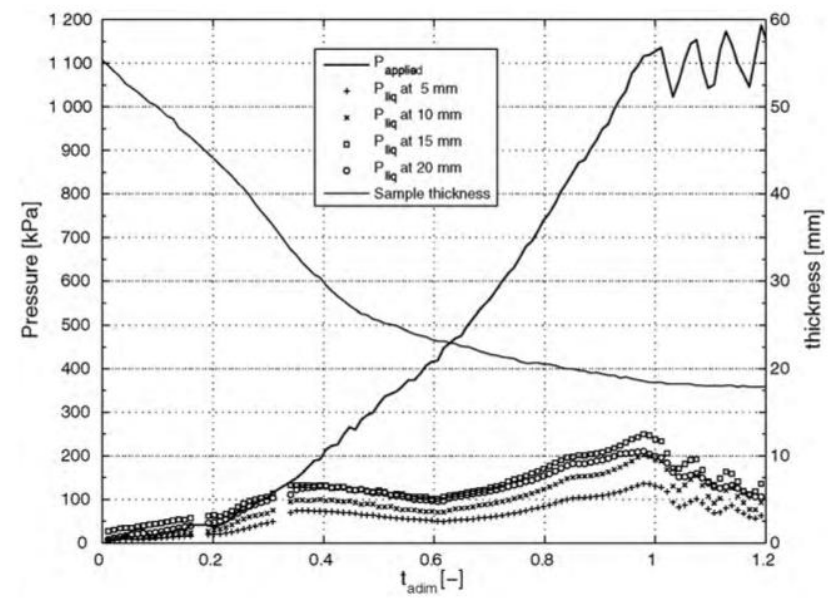

Figure 10: Liquid pressure histories for talc (full lines) and cellulose (dotted lines) suspensions dewatered at $1125 \mathrm{kPa}$ and ambient temperature

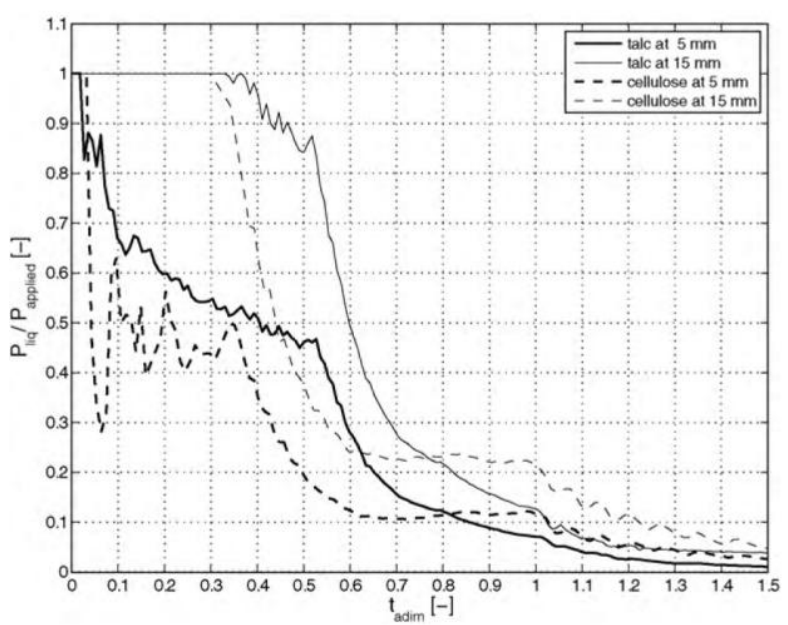


Figure 11: Liquid pressure profiles during talc suspensions dewatering at 1125 $\mathrm{kPa}$ and ambient temperature.

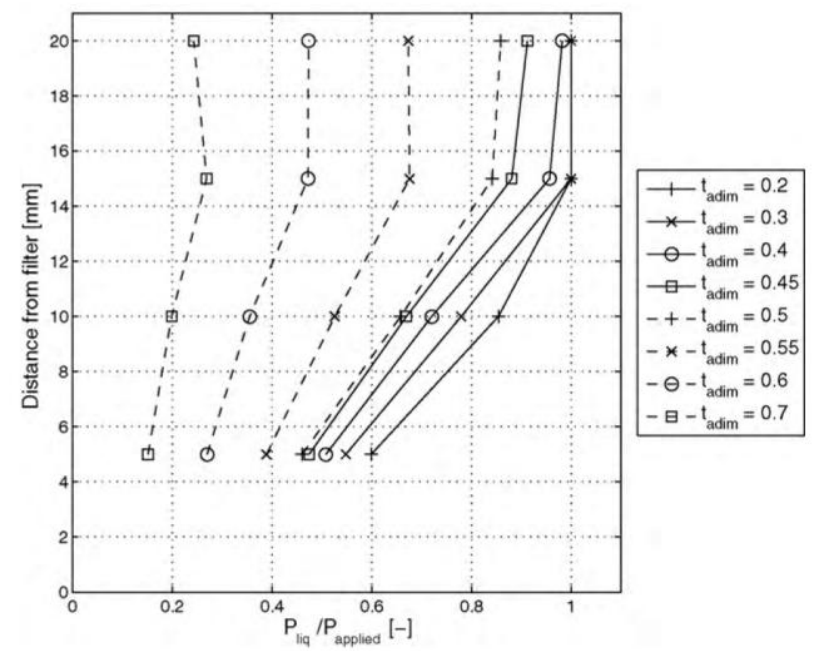

Figure 12: Liquid pressure profiles during cellulose suspensions dewatering at $1125 \mathrm{kPa}$ and ambient temperature.

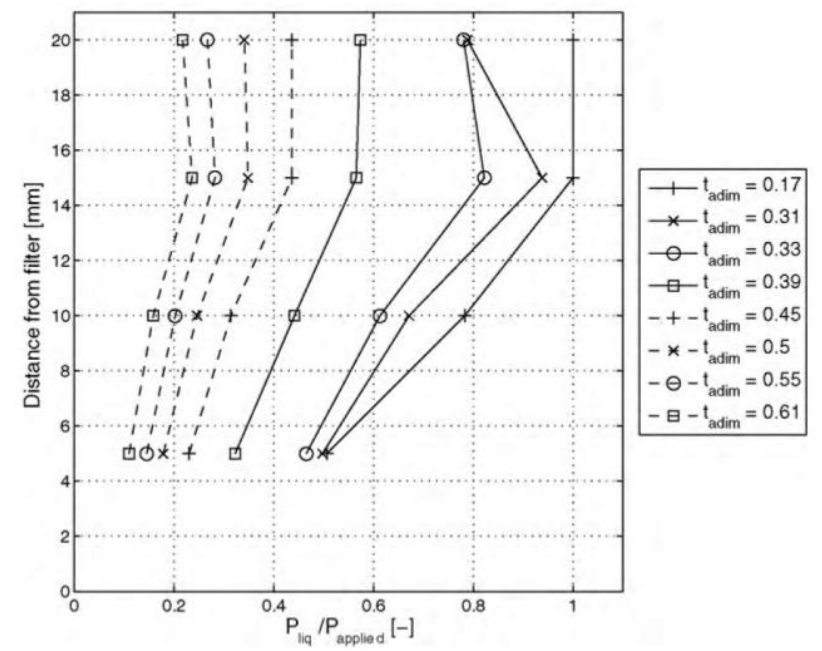


Figure 13: Cumulative masses of filtrate during dewatering experiments of talc suspensions

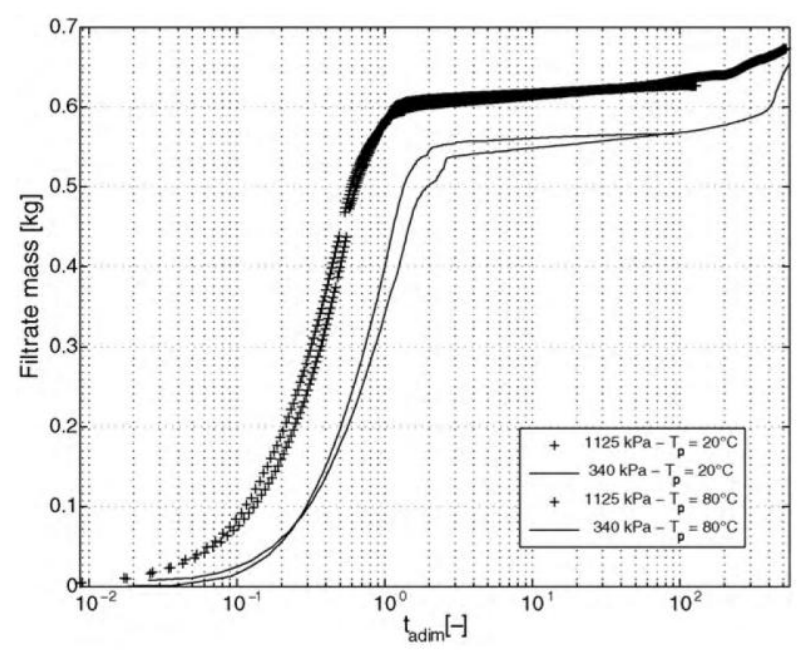

Figure 14: Cumulative masses of filtrate for talc and cellulose suspensions dewatered with the piston heated to $80^{\circ} \mathrm{C}$

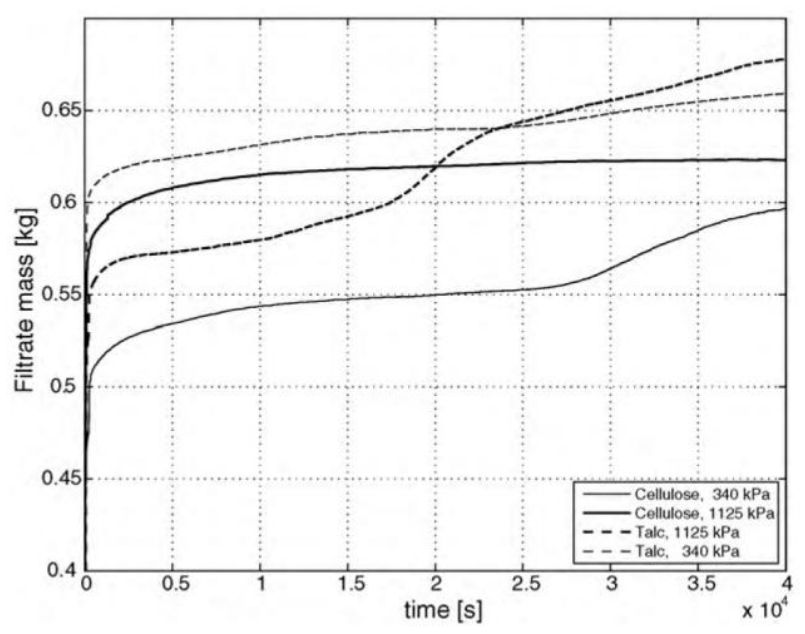


Figure 15: Liquid pressure histories for cellulose suspensions dewatered under $1125 \mathrm{kPa}$, at ambient temperature (full lines) or with the piston heated to $80^{\circ} \mathrm{C}$ (dotted lines)

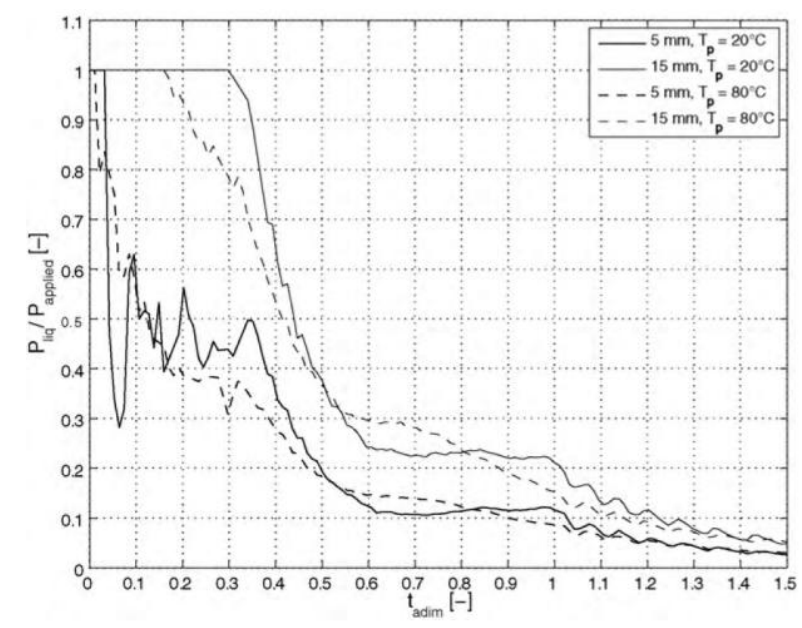

Figure 16: Cumulative mass of filtrate and temperature near the filter medium during cellulose dewatering at $340 \mathrm{kPa}$ with the piston heated to $80^{\circ} \mathrm{C}$

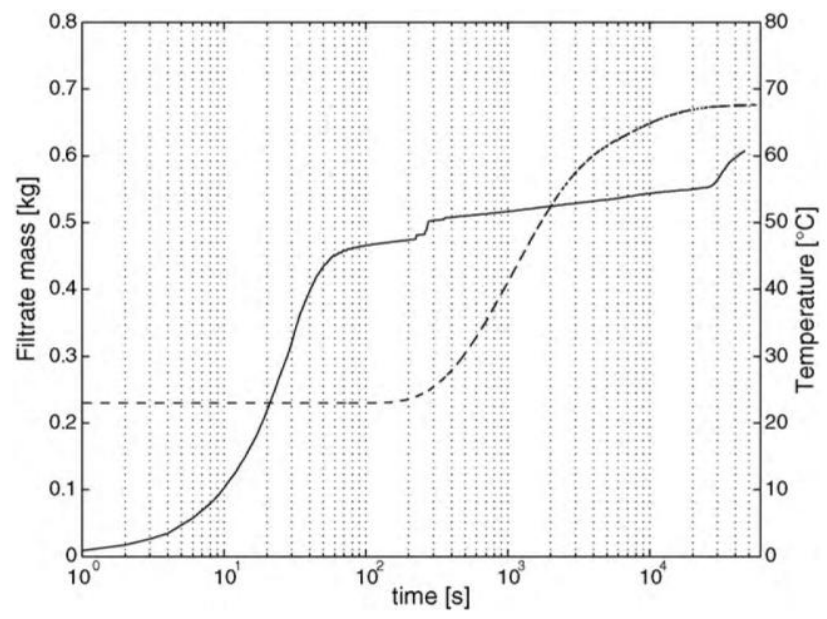


Figure 17: Liquid pressure gradient in a cellulose (left) and talc (right) cake in the thermally assisted process.
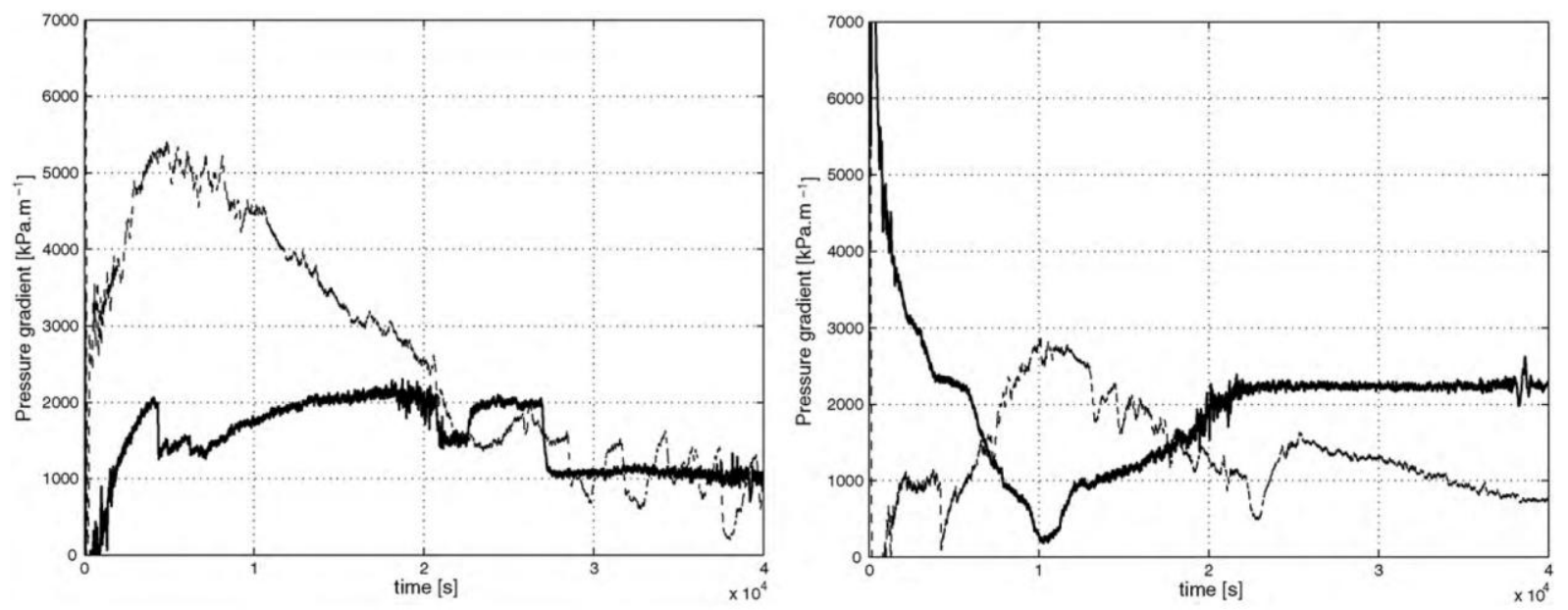


\section{References}

Chase, G. G. and Arconti, J., 1995, Stress-Strain Relation of Compressive Solka Floc Cakes. Journal of Food Engineering, 25(3): 373-386.

Clayton, S. A., Scholes, O. N., Hoadley, A. F. A., Wheeler, R. A., McIntosh, M. J. and Huynh, D. Q., 2006, Dewatering of biomaterials by mechanical thermal expression. Drying Technology, 24(7): 819-834.

Couturier, S., Valat, M., Vaxelaire, J. and Puiggali, J. R., 2003, Liquid pressure measurement in filtration-compression cell. Separation Science and Technology, 38(5): 1051-1068.

Curvers, D., Maes, K. C., Saveyn, H., De Baets, B., Miller, S. and Van der Meeren, P., 2007, Modelling the electro-osmotically enhanced pressure dewatering of activated sludge. Chemical Engineering Science, 62(8): 22672276.

Fathi-najafi, M. and Theliander, H., 1995, Determination of Local Filtration Properties at Constant-Pressure. Separations Technology, 5(3): 165-178.

Gachovska, T., Ngadi, M. O. and Raghavan, G. S. V., 2006, Pulsed electric field assisted juice extraction from alfalfa. Canadian Biosystems Engineering, 48(3): 33-37.

Grimi, N., Praporscic, I., Lebovka, N. and Vorobiev, E., 2007, Selective extraction from carrot slices by pressing and washing enhanced by pulsed electric fields. Separation and Purification Technology, 58(2): 267-273. 
La Heij, E. J., Kerkhof, P., Kopinga, K. and Pel, L., 1996, Determining porosity profiles during filtration and expression of sewage sludge by NMR imaging. Aiche Journal, 42(4): 953-959.

Lee, J. E., Lee, J. K. and Choi, H. K., 2007, Filter press for electrodewatering of waterworks sludge. Drying Technology, 25(10): 1649-1657.

Lu, W. M., Huang, Y. P. and Hwang, K. J., 1998, Stress distribution in a confined wet cake in the compression-permeability cell and its application. Powder Technology, 97(1): 16-25.

Mahmood, T., Zawadzki, M. and Banerjee, S., 1998, Pilot study of impulse drying industrial sludge. Environmental Science \& Technology, 32(12): 1813-1816.

Mahmoud, A., Fernandez, A., Chituchi, T. M. and Arlabosse, P., 2008, Thermally assisted mechanical dewatering (TAMD) of suspensions of fine particles: Analysis of the influence of the operating conditions using the response surface methodology. Chemosphere, 72(11): 1765-1773.

Peuker, U. A. and Stahl, W., 2001, Steam pressure filtration: Mechanical-thermal dewatering process. Drying Technology, 19(5): 807-848.

Ruth, B. F., 1946, Correlating Filtration Theory with Industrial Practice. Ind. Eng. Chem., 38(6): 564-571.

Sedin, P., Johansson, C. and Theliander, H., 2003, On the measurement and evaluation of pressure and solidosity in filtration. Chemical Engineering Research \& Design, 81(A10): 1393-1405. 
Shirato, M., Murase, T., Iritani, E., Tiller, F. M. and Alciatore, A. F. (1987). Filtration: Principles and Practices, Marcel Dekker, New York, USA.

Smythe, M. C. and Wakeman, R. J., 2000, The use of acoustic fields as a filtration and dewatering aid. Ultrasonics, 38(1-8): 657-661.

Tarleton, E. S., 1999, The use of electrode probes in determinations of filter cake formation and batch filter scale-up. Minerals Engineering, 12(10): 12631274.

Tarleton, E. S., 2008, Cake filter scale-up, simulation and data acquisition - A new approach. Journal of the Chinese Institute of Chemical Engineers, 39(2): 151-160.

Tiller, F. M. and Crump, J. R., 1977, Solid-liquid separation: an overview. Chemical Engineering Progress, 73(10): 65-75. 